\title{
More than just another addiction journal: KBS and social epidemiology come of age
}

Congratulations to those responsible for the first issue of the International Journal of Alcohol and Drug Research (IJADR). It is great to see a new addiction journal emerge under the auspices of the Kettil Bruun Society (KBS). If the society's vibrancy can be transferred to its new journal, it is likely to be a great success and could mature into a future trendsetter in the addiction field. In a field that is now dominated by genetics and neuroscience, it is very important to have the social, behavioral and population sciences presented and promoted in their own scientific journals. IJADR will not only be good for the field, it will also be good for the society by providing a vehicle for social scientists to communicate with one another across disciplines and between north and south. KBS has built a remarkable international network of social scientists, and the journal is a way for the people in the network to share methods, findings and theories. In doing so, it will facilitate the real work of translating the science into effective public policy, especially in the "emerging markets" where the emerging epidemics are now occurring.

So once the euphoria of greeting the first issue subsides, the journal will need to carve out an identity for itself. The field of journal editing is getting more complicated and "professionalized," which presents both challenges and opportunities for KBS. A two-tier system has emerged that separates journals that are indexed and abstracted in the international databases (thus assuring easy access to the articles published) from those that are not indexed. In order to navigate these and other complexities, it will be important for the editors to seek membership in the International Society of Addiction Journal Editors, and to work with them to become a major player in the marketplace of ideas.

As the number of professional organizations in the field has grown and those organizations have matured, there has been a concomitant growth in the number of specialty journals and the volume of scientific publications dealing with substance misuse. Between 1900 and I950, approximately 500 scientific articles were published per year on alcohol, and virtually none on illicit drugs. Between I950 and I970, the number of articles doubled each decade. By the late I980s more than 3,000 scholarly articles on alcohol were appearing per year, and the trend has continued unabated since then. A major part of this exponential growth is due to the number of addiction specialty journals that publish articles on alcohol and other drugs. There are now more than 85 addiction specialty journals, most of which have been established since the I970s (Babor, Morisano, Stenius, Winstanley, \& O'Reilly, 2008). The rapid expansion of scientific communication outlets and publication opportunities in the addiction field, of which IJADR is one example, is part of a larger process of steady growth in the field, and is certainly fueled by increased numbers of scientists and clinicians devoting their careers to addiction work. Without specialized scientific journals, the addiction field would not exist as we know it.

Contrary to the emphasis placed upon the biological and clinical sciences, some of the most important questions in addiction research reside in the domain of the social, behavioral and population sciences. At the very core of addiction research are questions about what drives population rates of drug and alcohol problems, why some populations have higher rates than others, and what societal interventions are effective in reducing those rates. It is therefore critical that this segment of the field develop a stronger set of communications options, and better ways to disseminate their research findings. IJADR should aspire to become not just a reporter of international trends in substance use, but also a player in the global policy arena.

Thomas F. Babor, PhD

IJADR Advisory Board

Regional Editor for the Americas, Addiction

Professor and Chair, Department of Community

Medicine, School of Medicine, University of

Connecticut, Farmington, CT o6o3o, U.S.A. 


\section{References}

Babor, T. F., Morisano, D., Stenius, K., Winstanley, E. L., \& O’Reilly, J. (2008). How to choose a journal: Scientific and practical considerations. In T. F. Babor, K. Stenius, \& S. Savva (Eds.), Publishing addiction science: A guide for the perplexed (2nd ed.). Brentwood, U.K.: MultiScience. 